\title{
Biomaterials: An Emerging Frontier
}

\author{
V.A. Ravi
}

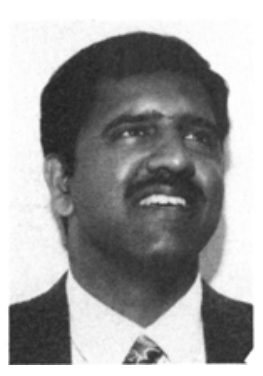

Materials engineering has played a prominent role in the advancement of several areas of human. endeavor. For example, every metallurgist is (or should be!) familiar with the role of steels in structural applications and of superalloys in aerospace applications. Not many of us, however, are aware of the significant role of metals, ceramics, and polymers in enhancing the quality of life for many individuals who have suffered devastating effects from the loss of limbs, joints, or other parts of the body. While stellar achievements such as the Jarvik artificial heart have been made famous in the popular press, a large number of engineers and surgeons are making significant, though not as well publicized, advances in the biomaterials area. ${ }^{1}$ For those who are unfamiliar with these developments, a fairly recent National Geographic article $^{2}$ presents an excellent summary of the different implants in the human body. Much of the information is distilled graphically in an image of the human form that is overlaid with implantable parts. The figure is titled "Rebuilding the Body from Nose to Toes."

Current research in biomaterials is driven by the need for implant materials to serve in the environment of the body while providing an opportunity for the patient to resume as normal a lifestyle as possible. In the past, most implant recipients were older people, and the implant lasted longer than the expected lifetime of the patient. Current trends, however, indicate that an increasing number of younger patients receive hip implants as a result of injuries sustained, for the most part, as a result of accidents or in the sports arena. This implies that implant materials not only have to survive longer but also have to withstand the rigors of a more active lifestyle. The large number of hip implants, 126,000 annually in the United States alone, ${ }^{3}$ indicates the importance of longer-lasting biocompatible materials. Some factors surrounding the pursuit of this durability are detailed on the following pages. In the first article, "Zirconium-Based Composites for Orthopedic Applications," Ravi, Claar, Berelsman, and Higgins outline the processing and properties of recently developed composite materials. The $\mathrm{ZrB}_{2}$-reinforced composite has several properties that are attractive for prosthetic device development. For example, the material has high flexural strength and fracture toughness, is amenable to electrical discharge machining, and can be polished to very fine finishes. The results of wear tests against ultrahigh molecular weight polyethylene (UHMWPE) indicate attractive properties relative to currently used materials (e.g., $\mathrm{Co}-\mathrm{Cr}-\mathrm{Mo}, \mathrm{Ti}-\mathrm{Al}-\mathrm{V}, \mathrm{Al}_{2} \mathrm{O}_{3}$, and $\mathrm{ZrO}_{2}$ ).

While it is imperative that the most appropriate material be chosen for the implant, the attachment of the device to the body is also critical. In his paper on the effect of metallic plasma-sprayed coatings on the high-cycle fatigue of titanium alloy orthopedic implants, Todd Smith discusses the use of porous coated implants as a potential method of reducing the chances for a loosening of the implant material. While this method has advantages over the use of bone cement in attaching the device to the body, it is important to evaluate the fatigue properties of implant materials with such coatings. Smith also discusses the highcycle fatigue testing of plasma-sprayed coatings on a Ti-6Al-4V alloy and demonstrates a significant decrease in highcycle fatigue performance. Thus, while the use of sprayed-coatings appears to be attractive as an attachment scheme, the designers should keep in mind the drop in fatigue properties.

On a different note, B.L. Zhou examines the lessons to be learned from natural materials and discusses how nature can be mimicked in designing materials. One of the important elements in his biomimetic study of composite materials is an examination of regenerative properties, which were observed in natural materials. For example, the concept of healing in a fractured bone is considered for its applicability to the design of materials. Although this field is in its infancy, Zhou's perspectives are very interesting and could well indicate the direction that composite materials design will take in the coming years.

\section{References}

1. J A Davidson and FS Georgette, Composites Applications-The Future is Now, ed. T J Drozda (Dearborn, MI Society of Manufacturing Enguneers, 1989), pp 397-422. 2. T.Y.Canby, National Geographic (December 1989), pp. 746-

3. S.J Mraz, Machtne Destgn (November 9, 1989), p 88

V.A. Ravi is a member of the technical staff at Lanxide Corporation in Newark, Delaware, and he is the advisor to JOM from the Structural Materials Committee of the TMS Structural Materials Division.

\section{Warning!}

\section{You may be in danger of losing your member benefits.}

\author{
If you have not already submitted your 1994 TMS dues payment, please do so immediately. \\ This will enable you to continue to receive the member discount for all TMS publication \\ purchases and conference registration, as well as uninterrupted delivery of JOM.
}

To continue your uninterrupted flow of TMS benefits, call TMS Member Services today at (412) 776-9000, ext. 236. 